\title{
PRÁTICA DOCENTE: SABERES E FAZERES NA ERA DA INFORMAÇÃO
}

\author{
TEACHING PRACTICE: KNOWING AND DOING IN THE INFORMATION AGE
}

\author{
Francisco de Assis Amorim de Araújo ${ }^{1}$
}

RESUMO: Este trabalho tem como objetivo analisar a prática pedagógica do professor, enquanto mediador do conhecimento, face aos saberes que fundamentam a aprendizagem dos educandos, em vista de sua autonomia para o exercício da cidadania. Aponta caminhos para uma prática docente em tempos de globalização. Fundamenta-se em teóricos como Tardif, Perrenoud, Bourdieu, Freire, Rios, Libâneo, Rego entre outros, que dão à instituição de ensino orientações à problematização dos desafios educacionais, a promover uma ação transformadora fortalecida pela razão coletiva que organiza um trabalho progressivo diante da contextualidade escolar. Para isso, segue um processo de pesquisa bibliográfica de natureza qualitativa no propósito de entender o homem como ser social e histórico. Assim, ressalta que os caminhos de aquisição do conhecimento convergem a uma humanização autêntica, dedicada ao ser humano em sua totalidade. Mostra como lidar com a diversidade, compreendendo o sentido da docência e das mudanças pedagógicas, exigidas no mundo atual.

Palavras - chave: Prática docente. Saberes. Fazeres.

ABSTRACT: This work has as objective to analyze practical the pedagogical one of the professors, while mediating of the knowledge, face to knowing them that they base the learning of the students, in sight of its autonomy for the exercise of the citizenship. It points ways with respect to one practical professor in globalization times. It is based on theoretical as Tardif, Perrenoud, Bourdieu, Freire, Rios, Libâneo, I among others writers, that they give to the education institution orientation to the problematization of the educational challenges, to promote a transforming action fortified by the collective reason that ahead organizes a gradual work of the pertaining to school context. For this, it follows a process of bibliographical research of qualitative nature in the intention to understand the man as to be social and historical. So, it stands out that the ways of acquisition of the knowledge converge to an authentic, dedicated humanize to the human being in its totality. Show as to deal with the diversity, understanding the direction of the practical teaching and the pedagogical changes, demanded for the current world.

Keywords: Practical teaching. To know. To make.

\section{INTRODUÇÃO}

Reflexão sobre a prática e o compromisso do educador frente as transformações e exigências atuais quanto a qualidade do trabalho educacional. O fazer pedagógico na organização dos saberes da docência, a visualização dos instrumentos que auxiliam no desenvolvimento e significação da

\footnotetext{
${ }^{1}$ Licenciado em Filosofia, História e Pedagogia. Especialista em Coordenação Pedagógica e Metodologia do Ensino de Filosofia. Mestre em Educação. Doutorando em Ciência da Educação. Atua como professor na rede pública de ensino da educação básica do Estado do Maranhão e em instituições privadas de ensino superior. Técnico pedagógico na Unidade Regional de Educação de Zé Doca - MA (URE/SEDUC).
} 
aprendizagem. A cooperação e sensibilização do docente e dos segmentos escolares à construção de uma vivência favorável ao desempenho de competências exigem uma reorganização da prática, utilizando-se a articulação dos saberes da docência como elementos indispensáveis à aquisição de conhecimento.

Esta temática parte da necessidade de maior fundamentação sobre o que os docentes, discentes e a escola em si, tem como desafio na realização do processo de ensino e de aprendizagem, como agentes atuantes em todas as dimensões da realidade onde se situam. Situa que as inovações da atualidade devem de forma prática, efetiva e eficiente contribuir para aprimorar os recursos do ensinar e aprender considerando a realidade da escola e do educando. Uma vez que, não se pode trabalhar o processo de ensino sem o envolvimento de seus atores com a realidade que forma $o$ contexto sociocultural da comunidade escolar. Dessa forma, visualiza o conceito de docência e a significação dos docentes frente a sua atividade profissional.

Ressalta, que a prática educativa no cotidiano escolar não se detém apenas em experiências já formadas e consolidadas, mas em relacioná-las ao conjunto de informações e vivências características do fazer docente e da aprendizagem dos estudantes. Para que diante das circunstâncias com as quais terá que enfrentar, possa atualizar as teorias epistemológicas ao propor novas situações de aprendizagem à comunidade estudantil. O que se entende por diversificação metodológica, que surgem e são consolidadas mediante a execução das práticas, tendo como foco a formação do entendimento reflexivo, para a humanização social e visão coerente da realidade em meio às suas contradições.

Seguindo uma linha reflexiva, fundamentada em análise bibliográfica, conclui-se que, os professores, precisam dividir seu mundo, seu entendimento para que possam refletir a realidade social da escola. Traçar metas à construção de sentido à educação como ciência do saber científico, suavemente e fundamentada com experiências práticas. Assim, a meta é colocar o estudante como sujeito do processo de aprendizagem na sistemática de ensino, para que ele possa conhecer e organizar o conhecimento.

\section{O SABER E O SABER FAZER NA DOCÊNCIA}

A sala de aula é o espaço privilegiado ao trabalho criativo, pois, educa corpo e mente para adquirir conhecimento na sistematização cientifica dos saberes por meio do fazer docente. $O$ educador pode direcionar seu trabalho para que os educandos entendam que "[...] a relação do homem com o mundo - é mediada pela excelência da linguagem, pois, ela carrega em si os conceitos generalizados e elaborados pela cultura humana" (REGO, 2002, p. 42). A expectativa é sempre que a prática pedagógica seja um envolvimento dos atores deste processo contribuindo para a evolução das concepções e consciência, na ação inteligente, afetiva e sensibilizadora ao crescimento cognitivo 
das pessoas. O caráter da apreensão do conhecimento e descoberta do mundo pela curiosidade ou pela dúvida disponibiliza aos educandos caminhos para pensar e planejar melhor as ações, aprendendo a ser humilde e tolerante quanto às diferenças e à partilha destas por meio do amadurecimento em relação às necessidades de interação com os outros.

Desta forma, o educador deve centrar seus esforços em meios de trabalhar a diversidade de modo a superá-las em vista da aprendizagem e do convívio social dos educandos. Nesse sentido, apropriar-se da realidade é um saber, que funda, relações de autonomia no processo histórico, pois, não se pode "[...] ser um simples espectador, a quem não fosse lícito interferir sobre a realidade para modificá-la” (FREIRE, 2006, p. 49). Tanto professor quanto aluno, neste sentido de contextualização, devem dar aos procedimentos metodológicos os objetivos para as mudanças, aliando esforços de acordo com as necessidades atuais e do por vir.

O docente estando atendo a realidade de seu cotidiano pode trabalhar a complexidade das situações por meio da problematização dos fatos, conduzindo-se por métodos pedagógicos bem claros, pois, seu trabalho deve, necessariamente, ser planejado para ações socioeducativas visando a linguagem universal do conhecimento, tendo o recurso didático, como significador do processo ensino-aprendizagem, nos critérios exigidos para uma aula produtiva, e de um fazer docente que pretenda realizar conquistas de cidadania. Nesse entendimento, o professor que negligência o planejamento em nome da "experiência" é bom que passe a "[...] reconsiderar seus pontos de vista, visando a começar a planejar suas atividades de ensino. Com essa providência lucrarão o próprio 96 professor e os alunos, a escola será mais conceituada na comunidade" (AYRES, 2004, p. III). Os docentes sabem como é difícil envolver adolescentes e jovens no intuito de visualizarem os diferentes ângulos abordados nas ações educacionais para ensino fundamental e ensino médio. Os mecanismos de abordagem pedagógica exigem conteúdo significativo quanto à interligação do saber teórico ao meio social e cultural na formação de conceitos claros, de modo a tornar a docência uma via de construção do saber, reafirmando as bases pedagógicas mediante as experiências, informações, debates e, enfim, no trabalho coletivo. De modo que haja maior proximidade entre educador e educando e inserção destes ao meio problematizado, enquanto trabalham a busca de soluções.

Daí, cria-se uma visão abrangente do mundo e aparecem novas possibilidades de trabalhar a realidade. Por meio desse claro entendimento as situações históricas apontam necessidades de inclusão dos entes da comunidade escolar, que deve ser antevisto nas predisposições do currículo da escola, criando espaços ao estudo teorizado, mas com perspectiva transformadora, que leva a escola em seu fazer, tornar-se um universo onde ninguém possa ficar fora do processo de construção do saber. Com isso, "[...] podemos entender esse processo como reflexão das ações humanas ao conjunto dos procedimentos que apreende à vida maneiras de conhecer" (FREIRE, 2005, p. 24), testando as 
qualidades, criando um conjunto de meios, determinando características e instrumentos de aplicação do ensino, antes compreendendo os passos e o que os educandos aprendem em cada aula.

Por isso, é interessante que o docente amplie constantemente seus níveis de saber para que haja em sua prática o desenvolvimento consistente do conhecimento, pois o que falta para se superar a inércia em diversificar os recursos auxiliadores da didática é insistir na formação continuada dos educadores; exigência essa profundamente enfatizada a todos os segmentos de profissionais, e, principalmente, os da educação, devido à necessidade de tornar a aprendizagem escolar um elemento atraente, com significado real à vida do educando. Isso seguramente remeterá à elaboração conjunta das atividades, tendo como foco a solução de problemas na leitura da realidade escolar, na diversidade que lhe é peculiar.

Essa esperança, que alimenta a articulação de uma pedagogia crítico-social, está na realização do trabalho contextualizado, que se faz eficaz à medida que as mudanças aparecem e pela reflexão sobre o próprio processo de aprendizagem. A formação acontece pela cooperação recíproca dos seguimentos da instituição de ensino (alunos, professores, coordenadores, gestores e colegiado), quando há interesse em consolidar desenvolvimento intelectual, autonomia dos sujeitos nos acontecimentos históricos e coerência valorativa do homem diante das condições que os sistemas lhe impõem na harmonização de seus interesses.

Um elemento não menos importante à competência do educador é conhecer os problemas da escola em sua origem, para acompanhar cada educando sem correr o risco de julgá-lo mal por um 97 comportamento ou outro. Esse modo de interação com a realidade que envolve a vida dos educandos permite um bom relacionamento e sensibiliza os colegas a fazer igual. Surge, então, a interdisciplinaridade como meta de currículo, que promove educação a partir da organização pedagógica "[...] integrando-se as condições de seu contexto, respondendo a seus desafios, objetivando-se, lançando-se o homem a um domínio que lhe é exclusivo - o da história e o da cultura" (FREIRE, 2006, p. 49), com a ideia de que a educação é contínua. E, é importante, para que isso se efetive que o educador diversifique sua prática articulando bem os saberes que as experiências têm construído. Esse processo dialético mostra que o profissional da educação já não pode pensar apenas em obter uma graduação acadêmica, mas desenvolver processos de atualização e incorporação de ferramentas, de instrumentos contemporâneos à atividade intelectual, que o leve a um sentido mais elevado de educação para os dias atuais.

Diante desta compreensão, surge um fator bastante interessante ser mencionando. Não se pode negar que falta ao professorado condições para que ele realize seu compromisso social de educador. Muitos participam de treinamentos e capacitação pedagógica, porém a prática continua a mesma porque não conseguem desenvolver ideias que permitam tornar o educando um sujeito de fato no processo de aprendizagem. Grande parte dos educadores ainda não considera que como 
agente do fazer docente devem favorecer aos discentes uma boa aprendizagem, buscando continuamente a formação de outros saberes, e meios de diversificar a prática na sala de aula. Uma exigência pertinente do processo educativo, à aquisição permanente de conhecimentos e engajamento para trabalhar utilizando diferentes formas de comunicar o ensino.

$\mathrm{Na}$ articulação do trabalho escolar não se pode perder de vista os princípios norteadores da docência. Que não sofrerão aqui demasiado detalhamento. Apenas sua importância e necessidade. O primeiro ponto importante nessa questão é a humanização, que aponta ao compromisso de valoração da pessoa enquanto ser que busca autonomia. O segundo é a democracia, que permite ações coletivas de construção e defesa dos interesses humanos voltados ao exercício da cidadania. O terceiro, e não menos interessante é a criatividade, que orienta a percepção de mundo tornando o educando participante ativo na construção de sua afirmação pessoal na sociedade. Isso é o que se defende como sistematização dialética de um processo, mostrando ser imprescindível que o professor crie com a criança ou o adolescente uma relação de diálogo e de situações em que eles apresentem os entendimentos que lhes são inerentes, assimilados em sua leitura particular do meio que presenciam e emitem opiniões. Saber ouvir, nesse caso, é uma habilidade que o educador não pode abrir mão, porque "[...] a educação é um processo de socialização da cultura, no qual se constroem, se mantêm e se transformam os conhecimentos e valores" (RIOS, 2002, p. 70). O educando precisa sentir-se útil, que suas ideias são válidas, para lançar-se mais ao estudo e obter um bom conhecimento.

Assim, para que a aula aconteça de forma dinâmica, vai depender em maior grau, da capacidade de inovação metodológica e do nível cultural do professor. Entendemos que a cobrança feita aos alunos, através das atividades escolares, será mediante as possibilidades que damos a eles de conciliarem avanços e retrocessos para haver desenvolvimento. Pois, tudo acontece satisfatoriamente na escola quando se tem objetivos claros e vontade de fazer um trabalho com responsabilidade social. $\mathrm{Na}$ educação os passos a serem dados devem, necessariamente, ser bemplanejado para não se correr o riso de fazer da escola, do trabalho docente e mesmo da aprendizagem dos alunos uma irrealidade.

O professor é o intelectual responsável pelo dinamismo do processo de aprendizagem escolar. Enquanto ele favorece por sua mediação pedagógica uma interação do estudante com a diversidade que o cerca, ele atribui sentido ao seu fazer e a educação passa, na visão do educando a ter significado, e lhe serve como propulsão a encontrar o sentido de sua atuação social no mundo.

\section{SITUANDO SUJEITOS E MECANISMOS DO FAZER DOCENTE}

Ensinar é uma prática que necessariamente conduz ou adverte o educador para o incessante progresso da linguagem cognitiva e intelectual humanizadora, em que ele utiliza mecanismos fortalecedores da ética para ser humano, de modo a tornar o mundo mais solidário às pessoas do que 
aos poderes. Nessa compreensão, competência em educação refere-se ao trabalho de organizar a aprendizagem em situações e atividades complexas com domínio dos saberes, "[...] dando auxilio, sem ser o especialista que transmite o saber, nem o guia que propõe a solução para o problema" (PERRENOUD, 200o, p. 35). É nesse ponto de vista, que as transformações, a partir da interação dos sujeitos no contexto socioeducacional, serão elucidadas.

Assim, podemos afirmar que por meio da mobilidade de entendimento ou ideias, podemos alcançar a essência da prática educacional, porque nas reflexões e conclusões sobre o ensino no sentido de apreender, aprender, construir e mudar ocorre um envolvimento, uma vontade dos docentes em fazer educação com competência. Isso ocorre, ao passo que todos entendem, “[...] que toda prática educativa demanda e existência de sujeitos, que um, ensinando, aprende, outro que, aprendendo, ensina - sendo o artífice de sua formação com a ajuda necessária do educador" (FREIRE, 2006, p. 7o). Uma cooperação responsável de comunicação e interação de saberes.

A docência, segundo Tardif (2006), é uma relação de aprendizagem constante desenvolvida por meio da integração dos entes da comunidade escolar, tendo como princípios básicos a complementação dos saberes e a comunicação clara e direta utilizando recursos dinamizadores do processo de ensino no enfrentamento das situações sociais e as exigências ao inter-relacionamento, que possibilite a aproximação das diferenças. Essa é uma ação pedagógica que visa mudança qualitativa ao ensino compreendendo as limitações pertinentes à prática educacional, a fim de promover a democratização dos estudos, envolvendo-se de estratégias facilitadoras da aprendizagem, 99 permitindo ao educando agir de forma autônoma e autêntica, "[...] compreendendo que os saberes estão ligados a uma programática: as representações do mundo que - proveniente de um coeficiente mais ou menos intuitivo de incerteza - pretende orientar as ações” (PERRENOUD, 20oI, p. 20), como engajamento à construção de sujeitos competentes na organização e progressividade dos entendimentos entre escola e sociedade à emancipação de seus atores.

Nesse sentido, o trabalho docente procura partir da real compreensão de autonomia da pessoa avaliando todas as dimensões que a sociedade requer aos parâmetros de educação, tendo em mente a conflitualidade em incorporar práticas sensibilizadoras, e, que ofereçam conteúdos de conhecimento inesgotável na dinâmica do ensinar e aprender apresentando valores em que homens e mulheres se constituam sujeitos historicamente situados e humanizados. Essa é uma compreensão muito claramente enfocada quando da realização de entrevistas, discussões e estudos a respeito de teorias e práticas da educação formal na sala de aula. Outra confirmação é que "[...] a falta de recursos e de tempo e a escassez de instrumentos pedagógicos são fatores materiais frequentemente mencionados pelos professores como estando entre as maiores dificuldades dessa profissão" (TARDIF \& LESSARD, 2005, p. 56). Contudo, a prática educativa não pode perder de vista a formação à 
cidadania. E isso, exige corresponsabilidade de professores e alunos compreendendo serem os principais sujeitos dessa jornada agindo mediante os desafios da contextualidade de tempo e lugar.

$\mathrm{Na}$ verdade, a necessidade educacional humana está em superar a problemática da vida social, compreendendo que não são as situações conceituais dessa ou daquela natureza, condicionamento implacável à afirmação ou fracasso do ser humano. Por isso, toda a dinamização das ralações entre teorias e práticas, na especificação dos saberes ou intensificação dialética do ensino, conforme Tardif e Lessard (2005) é um trabalho que tem por objetivo construir uma significação viva das relações pessoais criando possibilidades de ações sempre mais participativas.

Em decorrência das reflexões sobre os procedimentos docentes, a escola assume a responsabilidade de ser de fato parceira da sociedade dotando os sujeitos de capacidade intelectual, reflexão crítica e lhes fornecer instrumentos à organização institucional e cultural, de modo a mostrar sua pretensão de desenvolvimento e valor educativo. Desse modo, a prática necessita ser inclusiva antes de tudo ao próprio professor, para que ele possa reconciliar as dimensões da educação escolar e atenda competentemente às condições curriculares dispostas a seu trabalho, sendo à comunidade estudantil mediação e equilíbrio das relações em sala de aula. $O$ que na visão construtivista de ensino significa "[...] comunicar os objetivos das atividades aos alunos, ajudá-los a ver claramente os processos e os produtos que se espera que adquiram ou produzam" (ZABALA, 1998, p. 96), com o interesse, ainda, de sensibilizá-los à ação coletiva de construção do conhecimento nos diferentes níveis de aprendizagem.

Dessa forma, a transformação conceitual na identificação do papel da educação tem por interesse apontar a necessária evolução da mentalidade humana em realizar seus propósitos. Compreendendo, assim, que o conhecimento é o objetivo primordial do processo de formação e depende da autonomia da escola em trabalhar a interligação cultural do contexto social a que pertence, preocupando-se, também, em preparar espaços à consciência dos deveres e direitos do cidadão. Toda essa concepção educativa, que se empreende na contemporaneidade demanda uma preparação dos educadores, incorporando novos meios de aprendizagem por meio de habilidades que possam elevar as informações à categoria de conhecimento.

É preciso, para tanto, não haver dúvidas quanto ao significado da revolução da informação no meio escolar. O processamento das mudanças tecnológicas, hoje entendidas como exigência a todos os segmentos de profissionais, é na concepção de mudanças nos paradigmas sócioeducacionais, um acontecimento movido pela consciência da qualidade. Está alinhado à visão democrática da transitividade do ensino de um sentido ingênuo à criticidade, que possibilita inserção à ordem reflexiva, a qual leva educador e educando a assumir e "[...] refletir sobre sua ontológica vocação de ser sujeito" (FREIRE, 2006, p. II4). A gestão do conhecimento é, por esse intermédio, uma 
manifestação pública do que se pode fazer em diversos níveis de escolaridade para uma aprendizagem autêntica.

\section{DESAFIOS AO TRABALHO COMPETENTE EM EDUCAÇÃO HOJE}

Os desafios atuais ao fazer docente consistem em assimilar um universo de tecnologias na área da comunicação e informação, direcionando-as à educação. Aliás, a conclusão mais evidente é de que o sistema educacional a esse respeito ainda está tímido quando comparado ao sistema econômico, ao gerenciamento de empresas e negócios. Mas tem melhorado e sua inserção tem avançado, com maior volume de investimentos neste universo.

Isto, implica dizer que se está dando largos passos no sentido de superar a distância entre a evolução dos meios tecnológicos voltados ao trabalha escolar e a realidade das escolas. Isso representa exatamente o desafio ao qual os docentes precisam ter competência em lidar, no sentido de acompanhar os educandos, com atualidade de pensamento e habilidade no manuseio das ferramentas tecnológicas educacionais. Por isso, é necessário dar segurança ao estudante, para que ele envolvido por um grande volume de informações e culturas, onde ele possa discernir e agir com equidade neste novo universo de poder. Uma situação a qual não se pode fugir e que a escola a cada dia necessita se apropriar e significá-la para não perder o rumo da história.

Em meio a este contexto, é essencial também ter uma visão de futuro, pois olhando o passado, visualizamos uma cultura escolar menos dominada por grandes grupos econômicos, mas que apresentava um caráter extremamente elitista. A cultura como acesso ao conhecimento era algo de ambiente mais restrito. O livro, por exemplo, era algo para alguns privilegiados. Agora, trata-se de não jogar fora o imenso potencial que se abre "[...] para romper com a tendência de pensar o mundo social de maneira substancializada" (BOURDIEU, 2005, p. 48). Eis, porque se faz necessário entender o sentido da escola e do fazer docente, frente ao poder das grandes redes midiáticas, favorecendo meios de protagonismo estudantil, onde o educando seja sujeito de sua formação, tendo arbítrio sobre o que lhe seja importante e necessário à sua realização.

Nesse sentido, evidencia-se que, a escola, está com uma grande importância em sua missão humanizadora. Os interesses corporativos já buscam apropriar-se dela, objetivando, a partir das necessidades de consumismo cultural, equipá-las destes produtos colocando-os como instrumentos indispensáveis e facilitadores do fazer humano na atuação escolar. Isto demonstra, também, o interesse em envolver todos os segmentos sociais aos padrões de mercado, que aproxima os diferentes pontos do mundo na perspectiva de que ninguém se encontre isolado sem os devidos recursos de sobrevivência.

E o mais interessante dessas indagações todas, é que a compreensão de a educação com eficiência e qualidade não é, simplesmente, informatizar a sala de aula ou ter acesso a 'internet', mas, 
sobretudo, ter capacidade de repensar e reformular as práticas contextualizando-as através de uma linguagem dinâmica e universal, acontecendo a partir dos vínculos sociais internos e externos da instituição escolar. É dessa forma, que se entende o papel do educador e da educação em si, como agentes emancipadores do ser humano à vida e à cidadania.

Está claro, que mesmo existindo muita resistência às mudanças de pensamento de alguns professores, que relutam em não admitir que seja preciso fazer um processo de ensino-aprendizagem diferente, não se podem buscar soluções isoladas. Principalmente, se a realidade é multicultural. É essa dimensão do conhecimento, nas mais diversas manifestações, que mudou radicalmente, e exige cumplicidade entre os entes escolares para tornar o mundo menos individualista e promover maior afetividade sem deixar que seu destino seja decidido por outrem.

A dinâmica da cultura escolar frente ao desafio do modo de ensinar é segundo Pimenta (1999), um discurso ainda controverso com a prática real desempenhada pela maioria dos docentes. Essas mudanças de paradigmas causam uma revolução muito intensa no modo de conceber a educação e papel da escola hoje. Há no interior das instituições de ensino uma diversidade enorme de situações para as quais nem sempre se tem respostas ou mesmo se pode trabalhá-las sem um confronto direto com as ideias de quem está na escola, mas que demonstra descompromisso.

Eis que, a mudança tecnológica que a escola necessita sofrer está em vista da realização de uma aprendizagem significativa. Onde os instrumentos do trabalho docente tenham a finalidade de promover educação envolvendo conteúdo teórico, disciplina e ensino, procurando possibilitar às pessoas, por meio deste processo, autonomia e mentalidade crítica. Desse modo, o contexto interacional da sociedade educativa estará centrado no dinamismo do professor, desenvolvendo ciência e consciência, integrando-se às novas realidades e, em simultâneo, preocupando-se em está à frente das contradições aparentes.

O educador não pode se conformar com uma prática repetitiva de palavras, conteúdos e ideias inertes. Ele deve modificar as estratégias mediante as necessidades que se lhes vão aparecendo. Em relação aos instrumentos didáticos e seus objetivos de ensino, a 'internet' e outros programas midiáticos oferecem suporte à sistematização cientifica dos saberes sem exigir que o docente seja especialista em informática, mas que é fundamental na compreensão da cultura tecnológica. Sendo importante "[...] que os professores exerçam uma vigília cultural, sociológica, pedagógica e didática para compreender do que será feito a escola de amanhã, seu público e seus programas" (PERRENOUD, 200o, p. 138). É interessante, ainda, levantar hipóteses sobre quais saberes o profissional da educação deve se apossar.

Neste novo tempo de inclusão digital é importante ressaltar, que o processo de utilização da informática na sala de aula, até mesmo nas redes públicas de ensino, aponta um grande volume de recursos pedagógicos. Até mesmo o livro didático está sendo disponibilizados de forma eletrônica 
em diversas mídias, por meio dos quais estudantes e professores podem fundamentar os temas estudados e situar a aprendizagem. Esses saberes estão sendo democratizados no sentido de promover desenvolvimento de competências, habilidades, cidadania e visão de valores quanto a realidade atual. E por meio destes diversos saberes, o docente deve fazer dos recursos de mídia "[...] condições e modos de assegurar a relação cognitiva e interativa dos alunos com o objeto de conhecimento" (LIBÂNEO, 2006, p. 69). Além disso, ele, incontestavelmente, necessita explorar todas as formas didáticas e de programas, uma vez que, precisa ser abrangente nas questões complexas, imprimindo concentração à atividade produtiva de sua prática, desenvolvendo autonomia e eficácia ao processo de formação humana, tendo em mente a integralidade da pessoa.

É certo que o ser humano provoca transformações constantes ao mundo e às sociedades. Sendo assim, as relações de aprendizagem não podem deixar o educando assistir de maneira inerte a estes eventos. Ele deve ser sensibilizado a apresentar questionamentos e propostas de atuação dentro de uma visão de mundo peculiar às suas perspectivas. E o professor, então, não pode fugir da mediação dialética quanto ao contexto. Pois, só se chega aos resultados positivos dessas situações quando o projeto de emancipação é cumprido com compromisso na mobilização da mentalidade que garante a formação das competências necessárias. O processo de ensinar e aprender, partindo do cotidiano da sala de aula traz em si desafios que, o docente na reflexão de sua prática, necessita problematizá-los por meio de fundamentos educacionais científicos, para constituir saberes à sua atividade profissional. Isso deve conduzir a uma prática reflexiva sobre perspectivas e contexto para favorecer originalidade de conhecimento por meio da simbiose entre docentes e discentes.

\section{CONSIDERAÇÕES FINAIS}

Trabalho desenvolvido com a intenção de ressaltar, que o professor não pode, em hipótese alguma, abrir mão de manter uma postura incessante na busca por instrumentos viáveis e facilitadores do fazer docente, face aos desafios enfrentados na educação contemporânea. Neste sentido, vem afirmar a necessidade de se compreender o espaço educativo e, ao mesmo tempo, escolher um jeito significativo de desenvolver as situações de aprendizagem com os estudantes. De forma que, à docência responda às exigências vigentes postas e impostas pela sociedade, conforme os desafios que surgem. E, assim, realizar o seu trabalho ponderando as expectativas vislumbradas no processo e mensurar os resultados do trabalho educativo mediante atividades práticas que levem os educandos ao exercício da cidadania.

A compreensão mais abordada a esse respeito nas pesquisas já realizadas, é que o fazer docente tem como base a construção de caminhos à aquisição do conhecimento na articulação entre competência, habilidade e qualidade na aprendizagem, que são elementos indispensáveis a qualquer pessoa no século XXI. Pois, a aprendizagem é o ponto referencial de todo o processo interacional do 
ambiente escolar. É em função dela que o professor busca se capacitar no sentido de fazer a diferença na vida de cada estudante, ajudando-o a ter autonomia e estratégias crítico-criativas à superação de problemas e à significação dos desafios à realização de sua vida.

Em vista disso, é importante enfocar que a educação em primeiro lugar é um processo de dedicação ao ser humano em sua totalidade, livre de qualquer forma de preconceito ou medo. É acreditar que é possível desenvolver uma autêntica humanização sem deixar que a opressão dos sistemas, na sua tentativa de harmonizar seus interesses, faça educação um instrumento massificador da mentalidade social. Para isso, é necessário, consciência e responsabilidade diante das mudanças que a sociedade tem atualmente vivenciado.

O professor deve, portanto, ter a firme pretensão de agir no mundo atento a diversidade sociocultural, onde há muitos valores ou contra valores que tentem minimizar o ser humano ou negar-lhe seus direitos. Seu esforço é e será sempre de mover novos significados que comuniquem um posicionamento de reflexão da prática pedagógica em posição de vanguarda, para avivar os saberes à ação competente de sujeitos que constroem, porque trabalha a construção de conhecimento com autonomia de pensamento e profissionalidade.

\section{REFERÊNCIAS}

AYRES, Antonio Tadeu. Pratica pedagógica Competente: Ampliando os saberes do professor. Petrópolis: Vozes, 2004.

BOURDIEU, Pierre \& PASSERON, Jean Claude. Razões Prática sobre a Teoria da Ação. Campinas: Papirus, 2005.

FREIRE, Paulo. O que fazer: Teoria e Prática em educação popular. Petrópolis: Vozes, 2005.

Pedagogia da Autonomia: saberes necessários à prática educativa. São Paulo: Paz e Terra, 2006. LIBÂNEO, José Carlos. Adeus professor, Adeus professora? Novas exigências educacionais e profissão docente. São Paulo: Cortez, 2006.

PIMENTA, Selma Garrido (org). Saberes Pedagógicos e Atividade Docente. São Paulo: Cortez, 1999.

PERRENOUD, Philippe. Io novas competências para ensinar. P. Alegre: Artmed, 2000.

. Ensinar: agir na urgência, decidir na incerteza. P. Alegre: Artmed, 2oor.

REGO, Tereza Cristina. Vygotsky. Uma perspectiva histórico-cultural da educação. Petrópolis: Vozes, 2002.

RIOS, Terezinha A. Compreender e Ensinar: por uma docência da melhor qualidade. São Paulo: Cortez, 2002. 
TARDIF, Maurice. Saberes Docentes e Formação Profissional. Petrópolis, RJ: Vozes, 2006.

LESSARD, Claude. Trabalho docente: elementos para uma teoria da docência como profissão de interações humanas. Petrópolis: Vozes, 2005.

ZABALA, Antoni. A Prática Educacional: como ensinar. Porto Alegre: Artmed, 1998. 